Endocrinol. Japon. 1989, 36 (5), 767-773

\title{
NOTE
}

\section{Plasma Glucagon Response to Intravenous Alanine in Obese and Non-Obese Subjects}

\author{
TAKaShi ASANO, Hiroshi NINOMIYA, Kohtaro KAN, \\ TAKASHI YAMAMOTO AND MAKOTO OKUMURA
}

First Department of Internal Medicine, School of Medicine, Fukuoka University, 7-Nanakuma, Johnan-ku, Fukuoka 814-01, Japan

\begin{abstract}
To investigate glucagon (IRG) and insulin (IRI) responses to alanine infusion in obesity and to assess the effect of body weight reduction with respect to hormonal balance, we compared six obese subjects with nine normal weight controls. None of the subjects were diabetic by OGTT criteria. Plasma IRI and IRG were measured following IV alanine at a rate of $0.1 \mathrm{~g} / \mathrm{kg}$ over a period of $2 \mathrm{~min}$. Our obese subjects had an increase in IRG response to alanine, which was due to decreased suppression of alpha-cell function due to insulin resistance. Weight reduction via calorie restriction reduced insulin demand, resulting in reduced plasma IRI by restoring beta-cell function, and the IRG response was paradoxically decreased as compared with that before weight loss. It is conceivable that improvements in insulin sensitivity after body weight reduction may re-establish the normalization of pancreatic betacell function and the insulin-induced inhibition of IRG secretion. Our obese subjects were characterized by decreased IRG secretion which was reflected in a change in body weight reduction.
\end{abstract}

Obesity is characterized by excessive adipose tissue, resulting in hyperinsulinemia (Bagdade et al., 1967). However, the nature of the disturbance in plasma IRG is still controversial. Normal, exaggerated and suppressed pancreatic alpha cell functions have been reported under two different conditions, depending upon the kinds of patients studied and the methods employed (Walter et al., 1980; Kalkhoff et al., 1973; Wise et al., 1972; Schade and Eaton, 1974). Wise et al. (1972) found decreased secretion of plasma IRG in obesity using alanine as a stimulus, and Kalkhoff et al. (1973) reported increased secretion of IRG employing

Received April 4, 1989 arginine stimulation. Whether obesity is characterized by increased or reduced aminogenic glucagon secretion can be determined by examining the level of IRG secretion, thereby elucidating the metabolic state of the pancreatic hormone.

The present study was undertaken to evaluate the influence of obesity on hormonal balance with regard to IRI and IRG by employing L-alanine, the major gluconeogenic precursor and a potent stimulator of alpha cell function (Felig, 1973). To assess the influence of a low carbohydrate diet on IRG response, a re-examination of IRG and IRI response following alanine infusion was performed before and after body weight reduction in obese subjects. 
Table 1. Changes in body weight in obese and non-obese subjects.

\begin{tabular}{lccc}
\hline \hline & $\begin{array}{c}\text { Age } \\
(\mathrm{y})\end{array}$ & $\begin{array}{c}\text { Body weight } \\
(\mathrm{kg})\end{array}$ & $\begin{array}{c}\text { Body mass index }(\% \text { ideal body wt.) } \\
\left(\mathrm{kg} / \mathrm{m}^{2}\right)\end{array}$ \\
\hline Non-obese $(\mathrm{n}=9)$ & $21 \pm 0.7$ & $53 \pm 5$ & $19.8 \pm 0.3(94 \pm 6 \%)$ \\
\hline Obese $(\mathrm{n}=6)$ & & & \\
$\quad$ Before wt loss & $28 \pm 3.5$ & $89 \pm 12$ & $31.3 \pm 3.0(145 \pm 13 \%)$ \\
After wt loss & - & $81 \pm 9^{*}$ & $28.5 \pm 2.8^{*}(133 \pm 10 \%)$ \\
\hline
\end{tabular}

$* \mathrm{p}<0.05$ vs before body weight loss.

\section{Materials and Methods}

The response to alanine infusion was studied in two groups of subjects. One was composed of 6 obese subjects whose body weight was 45 per cent greater than their ideal weight and the second group was composed of nine non-obese subjects whose body weight was within 10 per cent of their idea1 weight (Table 1). All of the subjects appeared to be in good health and exhibited no evidence of diabetes mellitus, as indicated by $75 \mathrm{~g}$ OGTT.

The obese subjects were hospitalized and were fed a weight-maintaining diet containing 230$250 \mathrm{~g}(55-60 \%)$ of carbohydrate per day 5 to 7 days prior to testing, after which they were put on a diet restricting caloric intake $(25 \mathrm{kcal} / \mathrm{kg}$ ideal body wt), which included $160 \mathrm{~g}(50 \%)$ of carbohydrate for a period of 40-60 days. The OGTT $(75 \mathrm{~g})$ was performed for all subjects before starting the restriction of caloric intake.

Alanine infusion tests on obese subjects were performed before and after a program of weight reduction. Non-obese control subjects were also encouraged to eat at least $250 \mathrm{gm}$ of carbohydrate per day before the study.

After an overnight fast, L-alanine solution $(0.1 \mathrm{~g} / \mathrm{kg}$ as a $10 \%$ solution) was administered as an intravenous bolus for $2 \mathrm{~min}$. Blood samples were taken from a catheter in the other forearm vein when the subjects were in a basal state, prior to the infusion of alanine and at $3,5,10,15,20,30,40,50$ and $60 \mathrm{~min}$ after the start of the infusion. Plasma was separated and stored at $-20^{\circ} \mathrm{C}$ for the determination of glucose, IRI, IRG, free fatty acid (FFA) and alanine. Plasma IRG samples were collected in chilled tubes containing Trasylol (B) and Na2EDTA. Plasma glucose was determined by an automated glucose oxidase method. Plasma
IRI and IRG were assayed by a double antibody radioimmunoassay system with a Dainabot Kit. Plasma FFA measurement was done with an enzymatic assay kit (Kyowa Co., Ltd.). Alanine was determined by a microfluorometric enzymatic method (Karl et al., 1972). To analyze and compare the plasma IRG and IRI responses, the incremental areas from the baseline value for each hormone were calculated by trapezoid approximation. Student's $T$-test (paired and unpaired) was employed in the statistical analysis. Data in the text are expressed as the mean \pm SEM.

\section{Results}

Plasma glucose and insulin concentrations during $75 \mathrm{~g}$ OGTT in all subjects are shown in Fig. 1. Mean insulin response curves were significantly higher in obese subjects than in non-obese at 30,60 and 90 minutes.

\section{1) Non-obese subjects}

Basal plasma glucose, IRI, IRG and FFA concentrations are shown in Table 2. The plasma glucose concentrations following alanine infusion reached a peak of $91 \pm 3$ $\mathrm{mg} / \mathrm{dl}$ at $20 \mathrm{~min}$ and declined to $89 \pm 2$ $\mathrm{mg} / \mathrm{dl}$ at $60 \mathrm{~min}$. Plasma IRI increased significantly at $3,5,10,20$ and $40 \mathrm{~min}$ with a peak of $19.4 \pm 1.4 \mu \mathrm{U} / \mathrm{ml}$ at $5 \mathrm{~min}$. IRG in plasma rose significantly at all time points except at $60 \mathrm{~min}$, and a peak value of $128 \pm 17 \mathrm{pg} / \mathrm{ml}$ was found at $5 \mathrm{~min}$. 


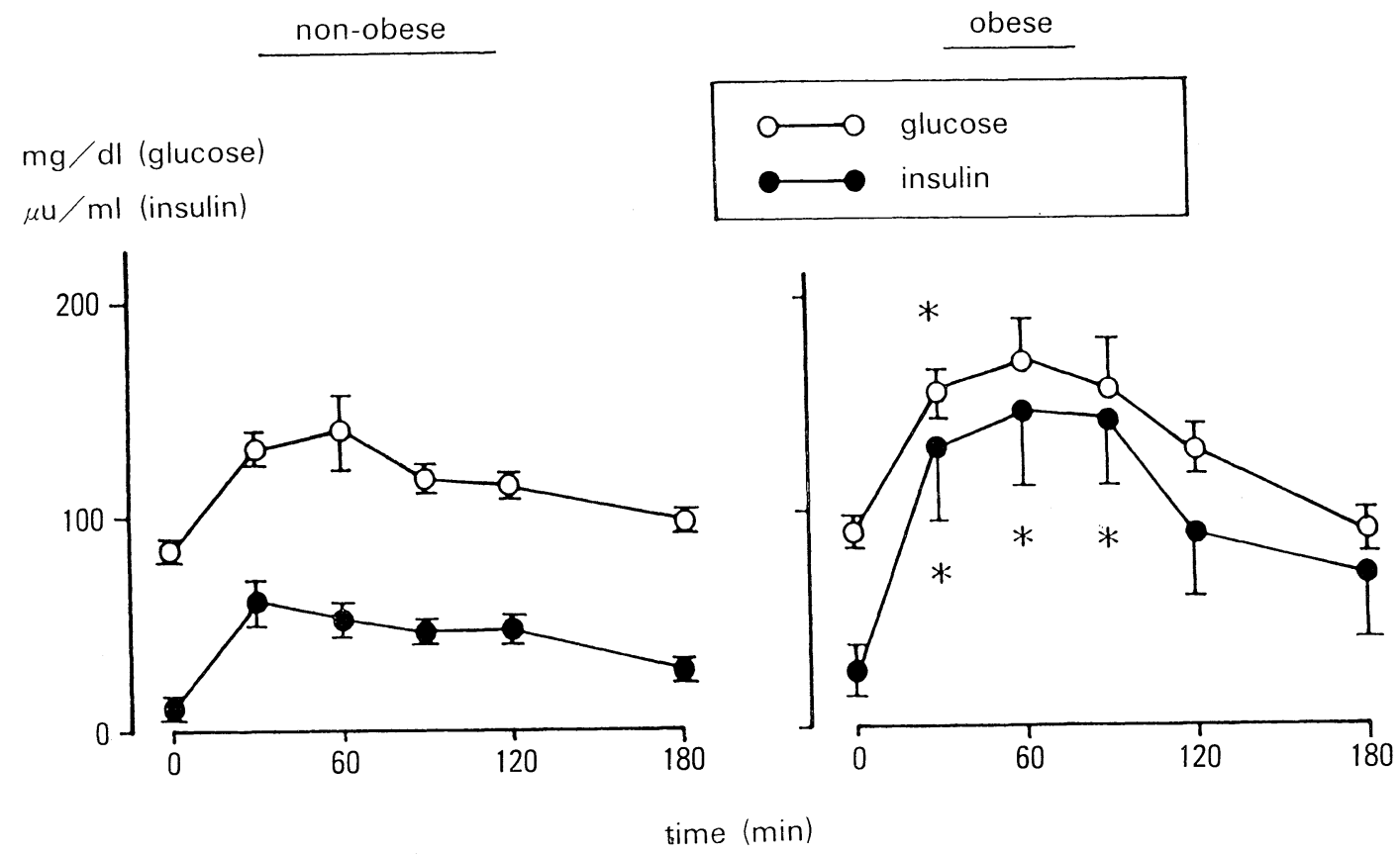

Fig. 1. Plasma glucose and insulin concentrations during $75 \mathrm{~g}$ OGTT in obesee subjects and non-obese controls. Asterisks express significant differences between the values in obese and non-obese controls $(\mathrm{p}<0.05)$.

Table 2. Basal levels of plasma glucose, IRI, IRG and FFA.

\begin{tabular}{lcccc}
\hline \hline & $\begin{array}{c}\text { Glucose } \\
(\mathrm{mg} / \mathrm{dl})\end{array}$ & $\begin{array}{c}\text { IRI } \\
(\mu \mathrm{U} / \mathrm{ml})\end{array}$ & $\begin{array}{c}\text { IRG } \\
(\mathrm{pg} / \mathrm{ml})\end{array}$ & $\begin{array}{c}\text { FFA } \\
(\mathrm{mEq} / \mathrm{l})\end{array}$ \\
\hline Non-obese & $82 \pm 2$ & $9.1 \pm 0.8$ & $80 \pm 11$ & $0.30 \pm 0.04$ \\
\hline Obese & & & & \\
$\quad$ Before weight loss & $81 \pm 3$ & $15 \pm 5$ & $56 \pm 8$ & $0.71 \pm 0.07 *$ \\
After weight loss & $78 \pm 3$ & $9 \pm 3$ & $47 \pm 10$ & $0.83 \pm 0.31^{*}$ \\
\hline
\end{tabular}

* : $\mathrm{p}<0.05$ vs non-obese

\section{2) Obese subjects}

Body weight was reduced by employing a low calorie diet as shown in Table 1. As shown in Table 2, there were no significant differences between basal values for obese and non-obese subjects except for plasma FFA $(\mathrm{p}<0.05)$.

A) Before body weight reduction (1eft panel in Fig. 2)

Plasma glucose increased significantly to a peak of $90 \pm 3 \mathrm{mg} / \mathrm{dl}$ at $20 \mathrm{~min}$ and paralleled an increase in the non-obese subjects. Plasma IRI increased to $36 \pm 7 \mu \mathrm{U} / \mathrm{ml}$ by $20 \min (\mathrm{p}<0.05)$ and remained significantly higher than the basal concentration until $60 \min (19 \pm 5 \mu \mathrm{U} / \mathrm{ml}, \mathrm{p}<0.05)$. The insulin level in obese subjects was significantly higher only at $20 \mathrm{~min}$ compared to the non-obese controls $(p<0.05)$.

Plasma IRG increased significantly at all sampling times except $60 \mathrm{~min}(\mathrm{p}<0.05)$. 

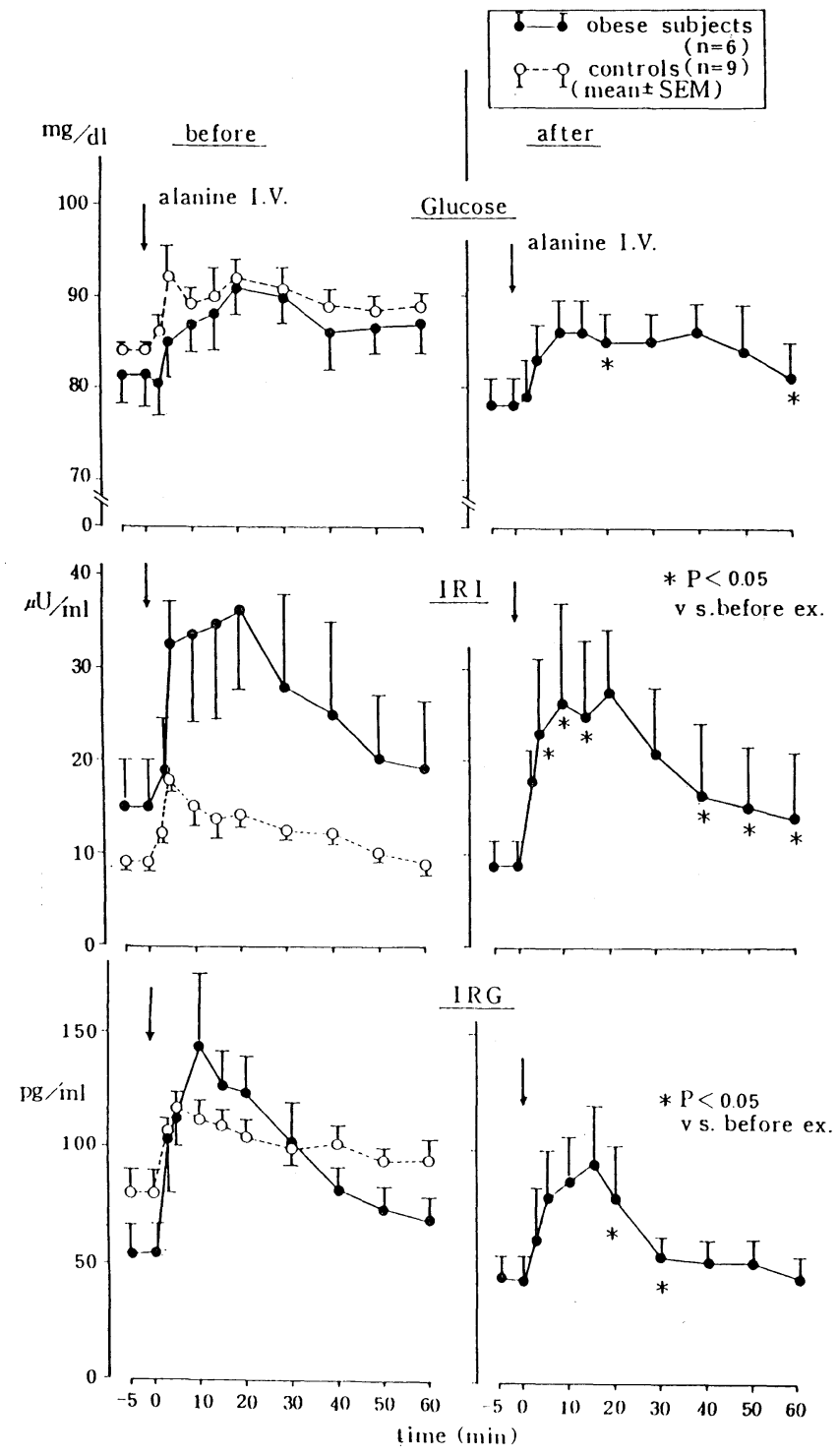

Fig. 2. Plasma glucose, insulin and glucagon concentrations following intravenous alanine infusions. In left panel, obese subjects before weight reduction and non-obese controls (broken lines); and in right panel, obese subjects after weight loss. Asterisks denote significant differences between the corresponding means before and after weight loss in obese subjects. $(\mathrm{P}<0.05)$.

Table 3. Mean values of incremental area from the baseline in response to IV alanine.

\begin{tabular}{lccc}
\hline \hline & $\begin{array}{c}\text { IRI } \\
(\mu \mathrm{U} / \mathrm{ml} / 60 \mathrm{~min})\end{array}$ & $\begin{array}{c}\text { IRG } \\
(\mathrm{pg} / \mathrm{ml} / 60 \mathrm{~min})\end{array}$ & $\begin{array}{c}\text { glucose } \\
(\mathrm{mg} / \mathrm{d} 1 / 60 \mathrm{~min})\end{array}$ \\
\hline Non-obese & $212.2 \pm 37.8$ & $1566.9 \pm 297.1$ & $363 \pm 87$ \\
\hline Obese & & & \\
$\quad$ Before weight loss & $689.0 \pm 212.2$ & $2764.9 \pm 483.4^{*}$ & $437 \pm 108$ \\
After weight loss & $640.7 \pm 314.8$ & $1196.8 \pm 241.3^{\mathrm{a}}$ & $390 \pm 91$ \\
\hline
\end{tabular}

$* \mathrm{p}<0.05$ vs non-obese.

$\mathrm{a} ; \mathrm{p}<0.05$ vs before weight loss. 
Table 4. Plasma alanine concentrations after the infusion of alanine.

\begin{tabular}{cccc}
\hline \hline & Non-obese & \multicolumn{2}{c}{ Obese } \\
& & Before weight loss. & After weight loss. \\
\hline Time in minutes & $(\mathrm{mM} / 1)$ & $0.288 \pm 0.020$ & $0.413 \pm 0.058$ \\
\hline 0 & $0.335 \pm 0.03$ & $4.334 \pm 0.517$ & $4.577 \pm 0.450$ \\
5 & $3.383 \pm 0.240$ & $2.687 \pm 0.408$ & $2.730 \pm 0.423$ \\
10 & $2.179 \pm 0.119$ & $1.490 \pm 0.175$ & $1.810 \pm 0.301$ \\
20 & $1.275 \pm 0.088$ & $1.037 \pm 0.097$ & $1.253 \pm 0.175$ \\
30 & $0.932 \pm 0.074$ & $0.834 \pm 0.062$ & $1.013 \pm 0.151$ \\
40 & $0.753 \pm 0.052$ & $0.692 \pm 0.070$ & $0.887 \pm 0.108$ \\
50 & $0.634 \pm 0.046$ & $0.541 \pm 0.051$ & $0.768 \pm 0.123$ \\
60 & $0.532 \pm 0.041$ & & \\
\hline
\end{tabular}

The peak value was $145.6 \pm 26.8 \mathrm{pg} / \mathrm{ml}$ at $10 \mathrm{~min}$, and decreased to $82.1 \pm 10.3 \mathrm{pg} / \mathrm{ml}$ at 40 minutes. The absolute plasma IRG concentrations in obese subjects did not differ significantly at any time from the corresponding values in the non-obese subjects. When the plasma IRG response was expressed as an increase in response to IV alanine above the baseline (Table 3), the obese subjects exhibited significantly higher values than the non-obese subjects $(\mathrm{p}<0.05)$. The mean increase in insulin in the obese subjects tended to be greater, but not significantly, than in the non-obese controls.

B) After body weight reduction (right panel in Fig. 2)

Plasma glucose concentrations after body weight loss were significantly lower at 20 and $60 \mathrm{~min}$ than before weight reduction $(\mathrm{p}<0.05)$, but there was no significant difference between the two studies in the increase in plasma glucose response. Plasma IRI response after weight loss was diminished at 5, 10, 15, 40, 50 and $60 \mathrm{~min}$ $(p<0.05)$. With regard to the plasma IRG response, there were significant differences between the before and after weight lossgroups at 20 and $30 \mathrm{~min}(\mathrm{p}<0.05)$. When compared to the non-obese subjects, plasma IRG concentrations in the obese subjects after weight reduction were also significantly lower at $3,40,50$ and $60 \mathrm{~min}(\mathrm{p}<0.05)$. As shown in Table 3, the difference in the increase between before and after weight reduction was significant $(\mathrm{p}<0.05)$ in the IRG response but not in the IRI response. In the non-obese and obese subjects after weight reduction, the difference in the cummulative enhancement of plasma IRI and IRG concentrations above the fasting value was not significant.

\section{Plasma alanine concentrations:}

The plasma alanine concentration in both groups after IV alanine infusion is shown in Table 4. Both groups had a similar alanine concentration, both before and after the infusion. The calculated mean rate constants of disappearance were $0.028 \pm 0.002$ $\min ^{-1}$ in non-obese subjects, and $0.030 \pm$ 0.001 and $0.024 \pm 0.002 \mathrm{~min}^{-1}$ before and after weight loss in the obese subjects, respectively. There were no statistically significant differences between these groups.

\section{Discussion}

Current information regarding IRG secretion is still unclear, although responses to oral glucose and beef in cases of obesity have been distinguished from responses in non-obese controls (Kalkhoff et al., 1973). Wise et al. (1972) found decreased secretion of IRG with alanine at a dose of $0.15 \mathrm{~g} / \mathrm{kg}$ body weight infused as a bolus over a period of $2 \mathrm{~min}$. Their diminished IRG 
response was accompanied by high plasma IRI concentrations. In the present study, the obese subjects had a significantly higher alpha-cell response to alanine infusion than non-obese controls, when the IRG response was expressed as an increase in plasma IRG. An increase response rather than the $a b-$ solute hormone level may allow better comparison between groups with different basal concentrations (Bagdate et al., 1967, Muller et al., 1971). Alanine-induced IRG release decreased significantly only after a low calorie diet over a period of 6-8 weeks. In obese and non-obese subjects, there was no significant difference in fasting plasma alanine levels $(0.288 \pm 0.02$ vs $0.335 \pm$ $0.03 \mathrm{mM} / 1$ ) in our study. On the other hand, the fasting plasma alanine in obese subjects, examined by Wise et al. (1973), was $0.4 \pm 0.05 \mathrm{mM} / 1$ and approximately twice the fasting plasma concentration in their non-obese controls. One might anticipate difficulty in stimulating IRG secretion with alanine infusion.

It has been reported that insulin suppresses IRG secretion in vitro (Maruyama et al., 1984; Samols and Stagner, 1988). In our study, a slightly potentiated IRG release was probably due to weaker suppression of alpha-cell function by pancreatic beta cell activity, since the cummulative response of IRI in obese subjects tended to be higher, but not significantly, than the corresponding values for the non-obese individuals. The hyperinsulin response which was noted only during OGTT could be interpreted as evidence of insulin resistance in obese subjects. Alanine is a potent stimulator of both IRI and IRG secretion (Eaton et al., 1972), but acts through a different mechanism from that of glucose to stimulate IRI secretion (Conway et al., 1978). Therefore, it might be unreasonable to expect an enhanced IRI response to alanine as evidence of insulin resistance.

After body weight loss in the obese subjects, the plasma IRG response was paradoxically decreased, accompanying lower plasma IRI secretion. These results indicate that calorie restriction resulted not only in a decrease in IRI secretion, but also in IRG release. It is usually accepted that insulin sensitivity improves after dietary treatment (Stanik and Marcus, 1980). It is conceivable that an improvement in insulin sensitivity may again normalize pancreatic beta-cell function and the insulininduced inhibition of IRG secretion.

A low carbohydrate diet was reported by Muller et al. (1971) to potentiate IRG. However, their low carbohydrate diet totalled 2300 calories and contained only $19 \mathrm{gr}$ of carbohydrate. Although the restriction of the carbohydrate intake in the case of obesity may have various effects on IRG metabolism, it would be expected that such a restriction in diet would result in a higher intra-pancreatic catecholamine concentration than with our less severe dietary restriction, thereby possibly increasing the effect of alpha-cell secretory function (Kaneto et al., 1975).

Several investigators have reported that an increase in plasma FFA caused suppression of IRG secretion in studies on dogs and human subjects (Schade and Eaton, 1974 ; Luychx and Lefebvre, 1970 ; Madison et al., 1968). The IRG response was not suppressed in our study, although high concentrations of plasma FFA were found. Obese subjects have been shown to have increased or normal FFA during fasting, suggesting that great variation exists in obesity (Opie and Walfish, 1963 ; Bagdade et al., 1969). Therefore, it is unlikely that high FFA concentrations alone may suppress the IRG response.

The regulation of pancreatic alpha-cell function may be mediated by a complex interaction between multiple factors that include neural influences, circulating fuels (FFA) and the peripheral insulin concentration. In addition, the close anatomical relationship between alpha and beta cells 
in the islets makes it very likely that alphacell secretion is influenced by the local concentration of other islet hormones (Samols and Stagner, 1988). Since obesity is normally characterized by a derangement of IRI secretion, one might expect to see this derangement reflected in the changes that occur in IRG secretion. Within the limits of our experimental design, a more satisfactory explanation of these data is that the plasma IRG concentration in obesity may be reflected in IRI metabolism.

\section{Acknowledgement}

Thanks are due to Morishita Pharmaceuticals, Osaka, for supplying L-alanine solution.

\section{References}

Conway, M. J., D. S. Schade, M. Buckman and R. P. Eaton (1978). The effect of altered autonomic tone on alanine induced insulin secretion. Horm. Metab. Res. 10, 290-294.

Eaton, R. P., M. J. Conway and M. Buckman (1972). Role of alpha-adrenergic blockade on alanine-induced hyperglucagonemia. Metabolism 21, 371-373.

Bagdade, J. D., E. L. Bierman and D. Porte, Jr. (1967). The significance of basal insulin levels in the evaluation of the insulin response to glucose in diabetic and non-diabetic subjects. J. Clin. Invest. 46, 1549-1557.

Bagdade, J. D., D. Porte, Jr. and E. L. Bierman (1969). The interaction of diabetes and obesity on the regulation of fat mobilization in man. Diabetes 18, 759-772.

Felig, P. (1973). The glucose-alanine cycle. Metabolism 22, 179-207.

Kalkhoff, R. K., V. V. Gossain and M. L. Matute (1973). Plasma glucagon in obesity. Response to arginine, glucose and protein administration. N. Engl J. Med. 289, 465467.

Kaneto, A., H. Kajinuma and K. Kosaka (1975).
Effect of splanchnic nerve stimulation on glucagon and insulin output in the dog. Endocrinology 96, 143-150.

Karl, I. E., A. S. Pagliara and D. M. Kipnis (1972). A microfluorometric enzymatic assay for the determination of alanine and pyruvate in plasma and tissue. J. Lab. Clin. Med. 80, 434-441.

Luychx, A. S. and P. J. Lefebvre (1970). Arguments for a regulation of pancreatic glucagon secretion by circulating plasma free fatty acids. Proc. Soc. Exp. Biol. Med. 133, 524-528.

Madison, L. L., W. A. Seyffert, R. H. Unger and B. Barker (1968). Effect of plasma free fatty acids on plasma glucagon and serum insulin concentrations. Metabolism 17, 301304.

Maruyama, H., A. Hisatomi, L. Orci, G. M. Grodsky and R. H. Unger (1984). Insulin within islets is a physiologic glucagon release inhibitor. J. Clin. Invest. 74, 2296-2299.

Mullar, W. A., G. R, Faloona and R. H. Unger (1971). The influence of the antecedent diet upon glucagon and insulin secretion. N. Engl. J. Med. 285, 1450-1454.

Opie, L. H. and P. G. Walfish (1963). Plasma free fatty acid concentrations in obesity. $N$. Engl. J. Med. 268, 757-760.

Samols, E. and J. I. Stagner (1988). Intra-islet regulation. Am. J. Med. 85 (suppl. 5A), 3135 .

Schade, D. S. and R. P. Eaton (1974). Role of insulin and glucagon in obesity. Diabetes $23,657-661$.

Stanik, S. and R. Marcus (1980). Insulin secretion improves following dietary control of plasma glucose in severely hyperglycemic obese patients. Metabolism 29, 346-350.

Walter, R. M. Jr., E. M. Gold, C. A. Michas and J. W. Ensink (1980). Portal and peripheral concentrations of insulin and glucagon after arginine infusion in morbidly obese subjects. Metabolism 29, 1037-1040.

Wise, J. K., R. Hendler and P. Felig (1972). Obesity: Evidence of decreased secretion of glucagon. Science 178, 513-514.

Wise, J. K., R. Hendler and P. Felig (1973). Evaluation of alpha-cell function by infusion of alanine in normal, diabetic and obese subjects. N. Engl. J. Med. 288, 487-490. 